\title{
School Psychologists' Perceptions Of Stakeholder Engagement In Response To Intervention
}

\author{
Suzanne Little, Central Washington University, USA
}

\begin{abstract}
As Response to Intervention (RTI) continues to be implemented in schools, it is important to consider how this initiative is perceived by the educational professionals involved in the implementation and effectiveness of the process. This study utilized a survey intended to investigate the perceptions of school psychologists regarding their engagement in the implementation of RTI, the systems level collaboration in implementing RTI, and engagement of other educational professionals (teachers, counselors, and administrators) in RTI. Over sixty practicing certified school psychologists in the Pacific Northwest completed an online researcherdesigned survey of their perceptions of RTI. The majority of participants reported that they were prepared to participate in RTI implementation, but they also indicated that RTI is not effectively implemented in a collaborative, team-based approach. Implications for training and practice and recommendations for future research are discussed.
\end{abstract}

Keywords: Response to Intervention; Perceptions of School Psychologists; Implementation of Response to Intervention; Collaboration

\section{INTRODUCTION}

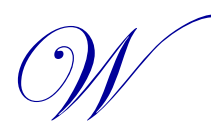

ith the implementation of Response to Intervention (RTI), the methods of delivery of educational services have begun to change in many schools throughout the country. These changes have affected many stakeholders such as classroom teachers, administrators, and educational specialists, including school psychologists. The implementation of RTI varies dramatically at the state, district, and individual school level (Powers, Hagans, \& Busse, 2008). Some studies have focused on the effects of the implementation of RTI on specific stakeholders and the perceptions of specific educational professionals, such as school psychologists (Sullivan \& Long, 2010; Kaplan, 2011; Mike, 2010; Sansosti, Telzrow, \& Noltemeyer, 2010); however, little research has explored the level of involvement of the various stakeholders, such as administrators, school counselors, and school psychologists. With collaboration among various educational professionals being a key in maximizing the effectiveness of RTI implementation (Nellis, 2012), all stakeholders need to be actively engaged in this initiative. The goal of this article is to briefly discuss the previous literature on the need for collaboration in RTI and to highlight the results of a survey of school psychologists' perceptions of stakeholder engagement in the implementation of RTI. Survey results on school psychologists' perceptions of their preparation for and involvement in RTI will be presented and implications for practice will be discussed. Finally, the engagement in educational professionals in RTI, from the perspective of the school psychologist, will be discussed and recommendations on collaboration in RTI presented.

\section{CURRENT LITERATURE}

\section{Response to Intervention (RTI)}

RTI refers to a comprehensive student-centered, assessment and intervention approach that incorporates a group of procedures that can be used to determine how students respond to changes in instruction over time (Canter, 
2006). It is a data-driven method for identifying and helping struggling students in need of more intensive instruction than what they experience in the general classroom (Brown \& Doolittle, 2008). Within RTI models, staff intervene early using a multi-tiered approach where each tier provides interventions of increasing intensity. According to the United States' National Research Center on Learning Disabilities (Johnson, et al., 2006, p.2), RTI is defined as

...an assessment and intervention process for systematically monitoring student progress and making decisions about the need for instructional modifications or increasingly intensified services using progress-monitoring data.

Historically, school psychologists have used the IQ-achievement discrepancy model to identify children with specific learning disabilities, but now they may use RTI in conjunction with or in place of the discrepancy model (Fuchs \& Fuchs, 2006; Fuchs, Mock, Morgan, \& Young, 2003). RTI is considered to be proactive and focuses on both prevention and intervention for students from preschool through high school and is the practice of providing quality instruction and intervention matched to individual student needs. Through RTI, one can monitor learning rate over time and level of performance to make important educational decisions to guide instruction (Elliot, 2008; National Association of State Directors of Special Education, 2005). Although RTI models of practice continue to be refined and developed (Crepeau-Hobson \& Sobel, 2010), like other changes, the shifts in roles and responsibilities brought about by RTI have caused concern among teachers, administrators, and other educational professionals alike.

\section{Changing Roles of School Psychologists in RTI}

With the implementation of RTI, there may be concern among education professionals, including school psychologists, in how their roles will be affected by the shift to a problem-solving approach such as RTI. Historically, the role of a psychologist has predominantly been that of psychometrist. Limitations of this focus, including the heavy reliance on the discrepancy model for identifying students with learning disabilities, are well documented. Specifically, in the "wait-to-fail" model, concerns such as a lack of focus on student strengths and weaknesses and the numbers of students that went unserved or under-served, are well-noted. However, in more recent years, the role of the school psychologist has transitioned into that of a problem-solver (Reschly \& Ysselydyke, 2002) requiring school psychologists to combine their understanding of psychology and education in order to provide the best service for the children with whom they work. School psychologists are now more often utilizing their strengths in collaboration, consultation, and interventions and are working in settings that allow them to engage in the delivery of a wider variety of services and to affect more students in meaningful ways. In research by Ysseldyke and colleagues (2006), school psychologists assisted with improving academic competence, social and emotional functioning, family-school partnerships, classroom instruction, and school-based child and family health and mental health services for all learners. As Fagan (2007) wrote:

With an opportunity for role expansion, RTI offers a challenge to the field of school psychology. Almost from the origins of school psychological services; there have been pleas for less time spent in assessment and more time with interventions. RTI is an opportunity for directing our services toward alternative assessments [and] more interventions. (p.6)

However, the role of the school psychologist in RTI is not clearly defined, but school psychologists' training in relevant issues, such as instructional methodology, assessment, and knowledge of research in the school setting, allow for school psychologists to be important members of the RTI implementation team (Burns \& CoolongChaffin, 2006). "Every school psychologist has the background to adapt and master RTI with a modicum of continuing professional development" (Fagan, 2007, p.6). This change in role from that of predominately psychometrician to more of a problem-solver will require school psychologists to be more open to change and additional training (Canter, 2006). Ultimately, if school psychologists expand their roles in RTI, there will likely be an increased need for school psychologists to take a leadership role in RTI.

\section{Roles and Leadership in Implementing RTI}

School psychologists can also play a leadership role in RTI. Lau, Sieler, Muyskens, Canter, Van Keuren, and Marston (2005) reported that there are significant implications for school psychologists and other educational 
professionals with the implementation of a problem-solving model such as RTI. Lau and colleagues completed a case study of how RTI impacts the roles of various school personnel, including teachers, administrators, and school psychologists. They noted that problem-solving models encourage the school psychologist to take a more prominent role as a problem-solver using their consultation skills in their work to identify interventions and measure student progress. School psychologists can also assist in facilitating system change that focuses on curriculum, instructional strategies, and support for diverse learners. Lau and colleagues (2005) also identified the implications that the implementation of the problem-solving model has for school personnel. They indicated the need for administrators to serve as change agents by communicating with teachers the need for change and the usefulness of the model. Additionally, administrators can support the move towards data-based decision-making and research-based practice. Thus, consultation and collaboration among all stakeholders in RTI is imperative.

The successful implementation of RTI is dependent upon leadership from stakeholders. Elliott (2008, p. 11) indicated that the importance of leadership for the implementation of RTI "cannot be underestimated." This is dependent upon several key components including a belief that all students can learn, the effective use of resources to increase student achievement, and an examination of what programs are working (or not). Additionally, consistent, high-quality professional development for all stakeholders is necessary and the reliance on data in decision-making must become the expectation for all stakeholders.

\section{Consultation and Collaboration in the Implementation of RTI}

Educational teams are not a new phenomenon. Educators often collaborate and use the expertise of many to provide the best possible services to students. The case of the implementation of RTI is no different. Specifically, RTI holds, as an expectation that professionals from a variety of disciplines and with a variety of experiences, will work together to effectively deliver services to students. This will require thoughtful collaboration (Knotek, 2005). Further, effective implementation of RTI requires collaborative planning and implementation by educational professionals throughout the school system (Elliott, 2008; Learning Disabilities Roundtable, 2005), and high quality teaming is critical for maximizing outcomes in RTI (Nellis, 2012). However, these teams are not implemented without addressing possible barriers. Nellis (2012) discussed potential barriers to implementing team-based practices including philosophical and practical barriers. According to Nellis (2012), philosophical barriers relate to beliefs and practices of building-level teams that conflict with the beliefs, practices, or goals of the school or the team process. Further, Nellis (2012) described practical barriers to teaming including logistical factors such as time, training, and team purpose and goals. Strategies for maximizing the effectiveness of teams were also suggested; some of those included were using a "systems change" approach, involving all stakeholders in discussions on RTI, articulating clear procedures for RTI, ensuring the availability of needed resources, supporting the high quality implementation of interventions, and providing on-going professional development. In order to implement these strategies, models of consultation can assist in providing opportunities for professional development and set the stage for the successful implementation of RTI.

There are numerous models of consultation used in school psychology, but two models that are perhaps most appropriate in implementing RTI include instructional consultation and consultee-centered consultation. According to Knotek (2005), instructional consultation (Rosenfield \& Gravois, 1996) is a "structured, systematic, and data-driven problem-solving consultation process focused upon improving the instructional ecology of schools" (p.101). A goal of this model is to reframe student concerns away from internal deficits but rather view them as a combination of instruction, task type and difficulty, and student existing skill level. Approaching the situation from this viewpoint allows the process to focus on curriculum and instruction. Another method is consultee-centered consultation which can be defined as emphasizing a non-hierarchical helping role in which the consultee and consultant work together to develop possible solutions to the identified problem. Knotek (2005) indicated that consultee-centered consultation is well-designed to support the implementation of the RTI. Specifically, this model is prevention focused, supports consultee work to develop possible solutions to identified concerns, and is applicable to both individual and school-wide practices.

\section{School Psychologists' Perceptions of RTI}

Even though the implementation of and research on RTI practices are increasing, only a few studies have examined the impact of RTI, specifically on school psychologists (Sullivan \& Long, 2010; Mike, 2010; Machek \& 
Nelson, 2010). In a survey of over five hundred members of the National Association of School Psychologists (NASP), Sullivan and Long (2010) found that $92 \%$ of the respondents reported having formal or informal training in RTI. School psychologists working in schools implementing RTI overwhelmingly reported involvement in the process (88\%). Further, Mike (2010) completed a survey of NASP members, and respondents indicated challenges of implementing RTI, including the need for professional development, lack of teacher preparation, lack of staff to implement interventions, and intervention fidelity. Finally, Machek and Nelson's (2010) survey of school psychologists revealed that they did not view themselves as qualified to take a leadership role in implementation of RTI. Sansosti, Telzrow, and Noltemeyer (2010) used focus groups to explore the perceptions of school psychologists regarding barriers and challenges to implementation of RTI in secondary schools. This study supported the notions of the need for involvement of many stakeholders in the implementation of RTI and of the collaborative nature of successful implementation of RTI.

\section{Research Questions}

Little research has studied the collaboration in and stakeholder engagement in RTI. Without buy-in and involvement by key stakeholders, RTI is likely to fail. Therefore, this study was designed to study school psychologists' involvement in and perception of stakeholder involvement in RTI. Research questions included:

1. Based upon their perceptions, do school psychologists feel prepared for and involved in the implementation of RTI?

2. Based upon the perception of school psychologists, are other educational professionals (teachers, counselors, administrators) aware of their role in and involved in the implementation of RTI?

\section{METHOD AND CONTEXT OF STUDY}

In further support of the above literature, a recent survey of school psychologists in a state in the Pacific Northwest was conducted. A total of 61 school psychologists completed the survey in its entirety. The survey was created by the researcher to explore questions related to school psychologists' perceptions of the involvement of educational professionals in the RTI process. The questions were designed to investigate the perspectives of school psychologists on their preparation for and involvement in RTI and their perception of the knowledge of and involvement in RTI of other educational professionals including teachers, counselors, and administrators.

\section{Participants}

Participants for the survey were recruited from a list of individuals holding school psychology certification within the state. Purposive sampling from a list of certified school psychologists in the state was utilized in order to sample practitioners from urban, suburban, and rural areas and to have representation from all geographic areas of the state. This was done due to the high concentration of population and school psychologists within a small geographic area of the state and in an effort to have better representation from practitioners around the state. Approximately 200 of the school psychologists certified by the office of the state superintendent of instruction were contacted via email and asked to participate in the survey. These participants were randomly selected from the list of certified school psychologists within the state after grouping them by their work in urban, suburban, or rural communities. Approximately five percent of the emails sent were undeliverable. Of the over 190 school psychologists whose emails were delivered, 61 completed the survey in its entirety. Approximately three participants completed less than half of the survey and their results were not included in this analysis.

\section{Methods}

The survey was developed by the researcher in order to study school psychologists' perceptions of educational professionals' involvement in RTI. Prior to data collection, the survey questions were reviewed by the researcher's academic colleagues and a small group of practitioners not participating in the survey. The survey was administered electronically and consisted of five demographic questions, four on collaboration in RTI and school psychologists' involvement in RTI, and two multi-part items inquiring about the knowledge of RTI and engagement in RTI implementation of various stakeholders. Other than the demographic items, the items were Likert-type with a 
forced-choice four option format. Participants were also able to provide narrative comments at the end of the survey. For the purposes of this paper, the demographic items were not extensively analyzed, but are briefly reported. The focus of the analysis was on the items regarding collaboration in RTI, school psychologists' involvement in RTI, and the narrative comments.

\section{Analysis}

Descriptive analysis of the items was completed to study the frequency of participant responses. Specifically, the number of participants agreeing or strongly agreeing with statements is reported and discussed. Further, patterns and themes in descriptive comments provided by the participants were analyzed.

\section{Relevant Results}

Participants included 61 practicing school psychologists in a state in the Pacific Northwest. Participants represented urban (over 50\%), suburban (approximately 30\%), and rural (nearly 15\%) districts. As shown in Figure 1 , over $60 \%$ of participants had eleven or more years of experience as a school psychologist, and over one-third of respondents worked only at the elementary school level. As shown in Figure 2, approximately $15 \%$ of participants indicated that they work only in the high school level and roughly $30 \%$ of respondents worked at multiple levels. The remaining participants reported working at middle schools (approximately 10\%) and other levels, including K-8 or 6-12 (approximately $11 \%$ ).

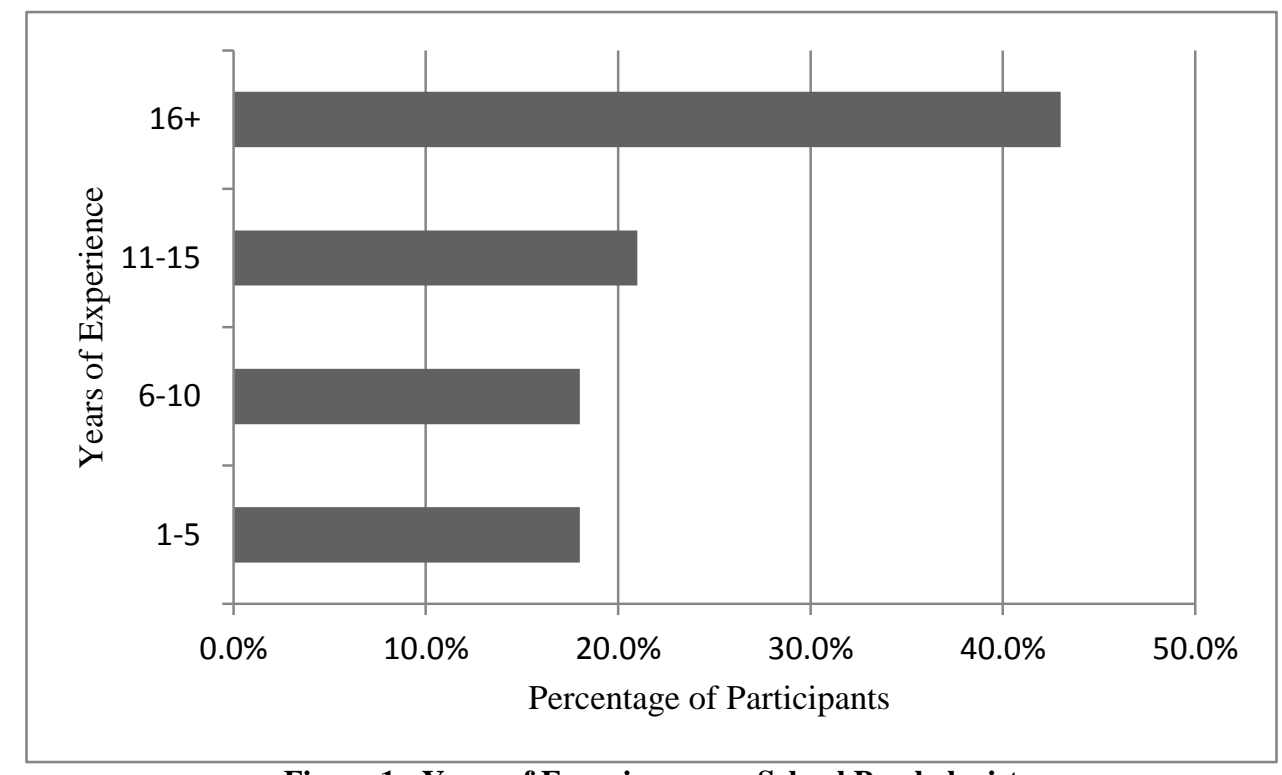

Figure 1: Years of Experience as a School Psychologist 


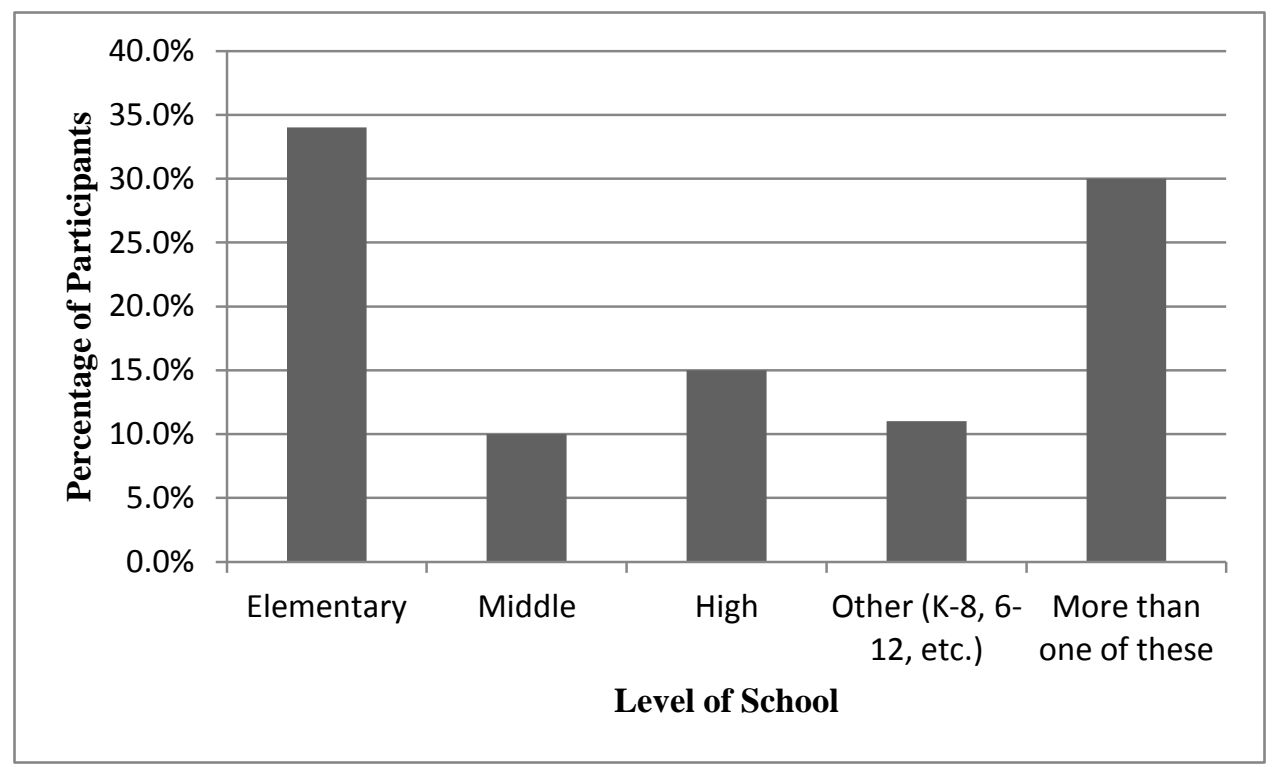

Figure 2: Level of Schools in Which Participants are Employed

An overwhelming majority of participants (over 85\%) indicated that schools in their district were implementing research-based interventions prior to assessment for special education services and most felt that they are well prepared to support the implementation of RTI in their schools. However, when asked if they felt that they are an integral part of the implementation of RTI in their schools, over $40 \%$ of respondents agreed or strongly agreed. Additionally, approximately half of respondents indicated that they work as a team to implement RTI in their schools.

While not part of the original research question, some participants commented on the varying stages of implementation of RTI in different levels of public schools. Respondents reported more success in the implementation of RTI at elementary schools and more challenges in implementing RTI in secondary schools.

The K-6 schools are being required to use only RtI for referrals. The 7 through 12 still use discrepancy; however, our middle school is (7th and 8th grade) doing some RTI.

At the 5th-7th grade building where I am based, we are attempting to implement Gen Ed interventions prior to evaluation. However, this does not always happen and data collection regarding the fidelity of implementation is basically non-existent, as far as I know.

One of my elementary schools is much further along in this process and has a better understanding than the other building where teachers are still highly resistant to the idea.

Respondents also completed a series of questions indicating the perceptions of school psychologists on the involvement of stakeholders in the implementation of RTI. Specifically, over one-third of respondents either agreed or strongly agreed that general educators understand the importance of their role in RTI and just less than one-half agreed or strongly agreed that general educators participate in the implementation of RTI. When surveyed about the involvement of special educators, over one-half of participants agreed or strongly agreed that special educators understand the importance of their role in RTI and are engaged in the implementation of RTI. Additionally, over one-half of participants agreed that school counselors are aware of the importance of their role in RTI and over onethird agreed that their school counselors are engaged in the implementation of RTI.

Leadership in the implementation of RTI is also important. When questioned about the support and engagement of school administrators and special education directors, participants indicated mixed results. Specifically, nearly two-thirds of participants indicated that school administrators in their buildings support the 
implementation of RTI and over three-quarters of special education directors support the implementation of RTI. Over half of respondents agreed that school administrators understand the importance of their role in RTI and over $70 \%$ agreed that special education directors understand their role in this initiative. Finally, over $40 \%$ of participants agreed that school administrators are engaged in implementing RTI and a similar number agreed that directors of special education are engaged in this process.

Several participants commented giving additional description of the status of stakeholder engagement in RTI in their schools:

At our high school, a core group of teachers and an administrator, as well as district level personnel, are working to implement RTI. Every staff person is not equal in their understanding of the process.

The special education director understands the importance but is not involved currently due to general ed really wanting to "do this." There is not much collaboration going on, but we are glad to see that RTI is being attempted.

\section{DISCUSSION}

This study provides unique insight into the status of the implementation of RTI and engagement of school psychologists and other educational professionals in RTI based on reports by school psychologists. Results such as these are important to school psychologists as individuals and schools look at systems of supporting student success and individually designed interventions. The ability of educational professionals to work together to meet the needs of all students, the challenges and barriers of doing so, and effective models of consultation and collaboration in RTI are worthy of discussion. Previous literature clearly indicates the need for all stakeholders to be engaged in RTI in order for it to be as successful as possible. With the expertise of various individuals coming together, students will be the beneficiaries of these multidisciplinary teams of professionals.

\section{Implications for Training, Practice, and Future Research}

Over $70 \%$ of respondents in the survey indicated that they were well prepared to support the implementation of RTI in their schools. However, less than half of participants indicated that they feel that they are an integral part of the RTI team in their schools. These results demonstrate that while school psychologists feel capable of participating in the RTI process, they are unlikely to feel they are an integral part of the implementation process. School psychologists have unique skills including data-based decision-making, consultation and collaboration, and knowledge of both human development and educational intervention which would lend them to be effective participants and leaders in the implementation of RTI. As noted by Canter (2006), school psychologists have numerous strengths to contribute to the implementation of RTI but need to be open to change and to additional training. Additionally, Machek and Nelson (2010) indicated that the majority of school psychologists perceived themselves to have adequate skills in the roles in RTI and approximately half of respondents in their study felt prepared to take a leadership role in implementing RTI. As more schools incorporate RTI as a means of identifying students with disabilities, there will very likely be additional significant changes in the role of the school psychologist, such as less traditional assessment and more involvement in data collection and analysis. These statements regarding role change could easily be said of general educators, special educators, school counselors, and school administrators as well. Professional development for all stakeholders regarding role and systems change would be beneficial. Finally, on-going professional development for school psychologists on RTI and specific training on RTI for pre-service school psychologists will enhance the ability of school psychologists to participate in and lead RTI teams.

This survey also examined the perceptions of school psychologists of the engagement of key stakeholders in the implementation of RTI. Participants reported that approximately half of general educators and special educators are engaged in the implementation of RTI. Further, respondents indicated that approximately one-third of school counselors, schools administrators, and special education directors participated in the implementation of RTI. In previous publications, Ryan, Kaffenberger, and Carroll (2011) discussed the importance of the role of the school counselor in RTI, and Lau and colleagues (2005) described the implications that the implementation of the problem solving model has for teachers, principals, and school psychologists. The collaborative nature of RTI teams has been 
discussed by Hoover and Love (2011) and Nellis (2012). Nellis (2012) also addressed both philosophical and practical barriers of teaming in RTI. Additionally, schools and school districts would be well-served to continue to work to successfully implement multidisciplinary teams to study the needs of and suggest strategies and interventions for struggling students. Further, training programs for pre-service school psychologists should continue to provide instruction and practical experiences for students in consultation and collaboration, particularly focusing on teaming and academic and behavioral interventions. Additionally, these results support the need for further professional development, including training on collaborative teaming, for all stakeholders. While this is by no means easy, the benefits for the students outweigh the challenges faced by the professionals. Additional research is needed to further evaluate successful collaboration in the implementation of RTI and on the perceptions of RTI and perceptions of engagement in RTI of other stakeholders (administrators, counselors and teachers).

Finally, the need for leadership in RTI has been described in previous literature (Hoover \& Love, 2011). In the current study, nearly two-thirds of participants indicated that school administrators in their buildings support the implementation of RTI and over three-quarters of special education directors support the implementation of RTI. This, too, has practical implications for training programs for educational leaders and for continued professional development for all stakeholders, especially administrators. Finally, additional research on the perceptions of educational administrators on the effective implementation of and teaming practices in RTI is warranted.

\section{Limitations}

Limitations of the current study include the small sample size and the lack of generalizability of the current sample across the profession due to the geographic area in which the data was collected. Further, the study focuses only on the perceptions of school psychologists and not on the perspectives of other educational stakeholders. Finally, the limited availability of demographic data makes it difficult to determine whether other factors, including gender and degree attainment, impact the perceptions of school psychologists on these issues.

\section{CONCLUSIONS}

Discussion exists about the implications of the implementation of RTI, including how RTI affects the roles of educational professionals and how RTI impacts student achievement. Originally, there was thought that the implementation of RTI would erase the need for school psychologists; however, it seems that RTI has and will continue to build on the strengths of school psychologists in several areas, including data interpretation and consultation. While the role of the school psychologist may undergo a transformation, school psychologists have much to offer in supporting and, in many cases, leading the implementation of RTI and in building consensus among other educational professionals.

\section{AUTHOR INFORMATION}

Suzanne Little, Ph.D., NCSP, is an Assistant Professor of Psychology and teaches primarily in the School Psychology program at Central Washington University in Ellensburg, WA. Her research interests include professional issues in school psychology, consultation and collaboration in school psychology, response to intervention, and assessment practices. E-mail: littles@cwu.edu

\section{REFERENCES}

1. Brown, J.E., \& Doolittle, J. (2008). A cultural, linguistic, and ecological framework for response to intervention with English language learners. Teaching Exceptional Children, 40(5), 66-72. Retrieved from http://cec.metapress.com/content/q391386q84347058/fulltext.pdf

2. Burns, M.K. \& Coolong-Chaffin, M. (2006). Response to intervention: The role of and effect of school psychology [Electronic version]. School Psychology Forum: Research in Practice, 1, 3-15.

3. Canter, A. (2006). Problem solving and RTI: New roles for school psychologists. NASP Communique, 34 (5).

4. Crepeau-Hobson, F., \& Sobel, D.M. (2010). School psychologists and RTI: Analysis of training and professional development needs. School Psychology Forum: Research in Practice, 4, 22-32. 
5. $\quad$ Elliot, J. (2008). Response to intervention: What and why? School Administrator, 65 (8), 10-12.

6. Fagan, T. (2007) Learning disabilities: Where's the satisfaction? Communique 35, 6.

7. Fuchs, D., \& Fuchs, L.S. (2006). Introduction to response to intervention: What, why, and how valid is it? Reading Research Quarterly, 41, 93-99.

8. Fuchs, D., Mock, D., Morgan, P.L., \& Young, C.L. (2003). Responsiveness-to-intervention: Definitions, evidence, and implications for the learning disabilities construct. Learning Disabilities Research and Practice, 18, 157-171.

9. Hoover, J.J., \& Love, E. (2011). Supporting school-based response to intervention: A practitioner's model. TEACHING Exceptional Children, 43 (3), 40-48.

10. Johnson, E., Mellard, D., Fuchs, D., \& McKnight, M. (2006). Responsiveness to Intervention (RTI): How to Do It. National Research Center on Learning Disabilities.

11. Kaplan, J.P. (2011). Massachusetts school psychologists' concerns regarding the implementation of responsiveness-to-intervention: A concerns-based adoption model approach (Unpublished doctoral dissertation). Northeastern University, Boston, Massachusetts.

12. Knotek, S.E. (2005). Sustaining RtI through consultee-centered consultation. The California School Psychologist, 10, 93-104.

13. Lau, M.Y., Sieler, J.D., Muyskens, P., Canter, A., VanKeuren, B., \& Marston, D. (2005). Perspectives on the use of the problem-solving model from the viewpoint of a school psychologist, administrator, and teacher from a large midwest urban school district. Psychology in the Schools, 43, 117-127.

14. Learning Disabilities Roundtable. (2005, February). Comments and recommendations on regulatory issues under the individuals with disabilities education improvement act of 2004, Public Law 108-446. Retrieved from http://www.nasponline.org/advocacy/2004LDRoundtableRecsTransmittal.pdf.

15. Machek, G.R., \& Nelson, J.M. (2010). School psychologists' perceptions regarding the practice of identifying reading disabilities: Cognitive assessment and response to intervention considerations. Psychology in the Schools, 47, 230-245.

16. Mike, K. (2011). School psychologists' preferences on response to intervention. (Doctoral Dissertation, University of Arizona). Retrieved from Dissertations \& Theses database. (AAT 3402014)

17. National Association of State Directors of Special Education (NASDSE), Inc. (2005). Response to intervention: Policy considerations and implementation. Alexandria, VA.

18. Nellis, L.M. (2012). Maximizing the effectiveness of building teams in response to intervention implementation. Psychology in the Schools, 49, 25-256.

19. Powers, K., Hagans, K., \& Busse, R.T. (2008). School psychologists as instructional consultants in a response-to-intervention model. The California School Psychologist, 13, 41-53.

20. Reschly, D.J., \& Ysseldyke, J.E. (2002). Paradigm shift: The past is not the future. In A. Thomas \& J. Grimes (Eds.), Best practices in school psychology IV (pp. 3-20). Bethesda, MD: National Association of School Psychologists.

21. Rosenfield, S.A., \& Gravois, T.A. (1996). Instructional consultation teams: Collaborating for change. New York: Guilford.

22. Ryan, T.R., Kaffenberger, C.J., \& Carroll, A.G. (2011). Response to intervention: An opportunity for school counselor leadership. Professional School Counseling, 14 (3), 211-221.

23. Sansosti, F.J., Telzrow, C., \& Noltemeyer, A. (2010). Barriers and facilitators to implementing response to intervention in secondary schools: Qualitative perspectives of school psychologists. School Psychology Forum: Research in Practice, 4, 1-21.

24. Sullivan, A.L., \& Long, L. (2010). Examining the changing landscape of school psychology practice: A survey of school-based practitioners regarding response to intervention. Psychology in the Schools, 47, 1059-1070. doi: 10.1002/pits.

25. Ysseldyke, J.E., Burns, M., Dawson, P., Kelley, B., Morrison, D., Ortiz, S., Rosenfield, S., \& Telzrow, C. (2006). School psychology: A blueprint for training and practice III. Bethesda, MD: National Association of School Psychologists. 


\section{$\underline{\text { NOTES }}$}

